\title{
Investigation of the Dyeability Behavior of Banana Fibers with Natural Dye Extract Obtained from Turmeric Plants
}

\author{
Seyda CANBOLAT ${ }^{1}$, Nigar MERDAN ${ }^{1}$, Habip DAYIOĞLU ${ }^{1}$, Dilara KOÇAK ${ }^{2}$ \\ ${ }^{1}$ Istanbul Commerce University, Faculty of Engineering and Design, Department of Fashion and Textile Design, \\ Istanbul, Turkey \\ ${ }^{2}$ Marmara University, Faculty of Technology, Department of Textile Engineering, Istanbul, Turkey
}

\begin{abstract}
In this study, the fibers produced from the banana plants provided from Antalya region were treated with a variety of mordants, and then the fibers were dyed with the natural dye extracted from turmeric plant (Curcuma longa) via ultrasonic and conventional method. Finally, the dye uptake and fastness properties of samples were investigated. The recent studies have demonstrated that the synthetic dyes can be non-biodegradable, allergenic, cytotoxic and partially carcinogenic. Recently demand for eco-friendly, non-carcinogenic and non-toxic products have been gradually increased. Compared to the synthetic dyes, the natural dyes are advantageous in the way of been biodegradable and non-toxic and not causing health problems, produced under temperate conditions. These properties of natural dyes lately result in increasing their usage. Today utilization of many plant extracts as natural dyes has been investigated such as turmeric plant.
\end{abstract}

Keywords: Banana Fibers, Natural Dyes, Dye Uptakes, Fastness Properties, Ultrasonic Method, Conventional Method.

\section{INTRODUCTION}

Dyeing of textile materials trace back to ancient times. Through the ages, textile materials have been dyed with the natural dyes provided from the animal and herbal sources [1]. By the use of natural dyes decreased with discovery of synthetic dyes in 1856 [2,3]. The synthetic dyes are preferable as they provide a wide range of color, being cheap, easier to supply and their fastness properties [4]. The recent studies have demonstrated that the synthetic dyes can be non-biodegradable, allergenic, cytotoxic and partially carcinogenic $[5,6]$. Recently demand for eco-friendly, noncarcinogenic and non-toxic products have been gradually increased. Compared to the synthetic dyes, the natural dyes are advantageous in the way of been biodegradable, nontoxic $[7,14]$ and not causing health problems, produced under temperate conditions. These properties of natural dyes lately result in increasing their usage [8-11]. Today utilization of many plant extracts as natural dyes has been investigated such as turmeric plant. Turmeric which includes yellow pigments is grown in tropical climates and used as spices. Turmeric, which includes yellow pigments is grown in tropical climates and used as spices [12]. Turmeric, the main component of which is curcumin, has the derivatives of dimetoxicurcumin and bis-dimetoxicurcumin (Figure 1).
There are several of studies explaining this plant is antibacterial, anti-microbial, and anti-oxidant and prevents inflammation [13]. In addition to the eco-friendly nature of the dyes and the auxiliary chemicals used in coloring of textile materials, maintenance of energy consumption at the optimum level is of significance.<smiles>COc1cc(/C=C/C(=O)CC(=O)/C=C/c2ccc(O)c(OC)c2)ccc1O</smiles>

Figure 1. The structure of curcumin [1]

Compared to the ultrasonic process and the conventional process, the ultrasonic energy accelerates the chemical and physical reactions at the dyeing process $[15,18]$. This effect results in occurrence of dyeing process at low temperatures, which, in turn, optimizes the use of heat energy. Besides, compared to the fastness of materials which were dyed via conventional method, the colour fastness of materials which were dyed via ultrasonic method is better $[16,17$, 20, and 21]. As a result of the above mentioned study, the

Corresponding Author: Şeyda CANBOLAT, Tel: +90 (212) 28561 83, E-mail: scanbolat@ticaret.edu.tr

Submitted: 15 October 2014, Revised: 04 March 2015, Accepted: 01 July 2015 
ultrasonic method provides an eco-friendly dyeing process providing low dye bath temperature, shorter dyeing period, low electrolytes as well as low dyestuffs content $[18,19]$.

In this study, the fibers have been procured from the stem of banana plants. The banana plants used in this study provided in Antalya region. After the banana fibers provided, the fibers mordanted with a variety of mordants and finally the fibers have been dyed with the natural dyestuff which was extracted from turmeric plants by ultrasonic and conventional method. Finally the dye uptakes and the colour fastness behaviour of the samples have been investigated with regards to the mordents and the natural dyes.

Although turmeric plant is quite expensive material, our purpose of using is its colour as well as its healthy properties of which may effect human body through in touch on the human skin.

\section{EXPERIMENTAL}

\subsection{Scouring Process}

The banana fibers weighing 5 grams were applied to the scouring process in 3\% sodium hydroxide solution (based on the weight of the fiber: o.w.f) at the boil for one hour before have been neutralized with acetic acid and finally the samples dried.

\subsection{Mordanting Process}

The banana fibers were mordanted with a variety of mordent before the dyeing process. The samples were undergone the mordant process at the boiling temperature for 60 minutes in the mordent liquors prepared in the mordent liquors ratio of $1 / 20$ with a variety of mordent with regard to the material weight. The conditions of the mordanting process are explained in Table 1.

\subsection{Preparation of Dyeing Extracts}

In this investigation the dyeing solution was prepared by using 1 gram of turmeric and $200 \mathrm{ml}$ of distilled water.

\subsection{Dyeing Process}

For the dyeing process, 2 grams of materials subjected to the application of pre-mordant process by boiling with the dyeing solution prepared with the liquor ratio of 1:20 for one hour. Then, the dyed samples were removed from the liquor and left to cooling. After this procedure the samples were washed with cool water and they were left to dry. The experimental conditions of the dyeing process with mordant and without mordant take place in Table 2 .

The dyeing process was carried out with Maxwell Ultrasound Dyeing device at $70{ }^{\circ} \mathrm{C}$ with the liquor ratio of $1: 20$ for 15 minutes and the samples were exposed to $20 \mathrm{kHz}$ ultrasonic power. Finally the samples were rinsed with cold water, hot water and again cold water respectively.

Table 1. Mordanting process

\begin{tabular}{|c|c|c|c|c|}
\hline Code & $\begin{array}{c}\text { The } \\
\text { Quantity } \\
\text { of } \\
\text { Mordant } \\
\% \text { (o.w.f) }\end{array}$ & Mordant & pH & Conditions \\
\hline 1 & 4 & $\begin{array}{l}\text { Copper } \\
\text { Sulphate }\end{array}$ & 5 & \\
\hline 2 & 15 & Alum & 4 & 5 grams of mate- \\
\hline 3 & 4 & $\begin{array}{l}\text { Ferrous } \\
\text { Sulphate }\end{array}$ & 5 & $\begin{array}{l}\text { rials were treated } \\
\text { in } 40 \mathrm{~mL} \text { liquor } \\
(1: 20) \text { at the boil } \\
\text { and finally for } \\
60 \text { minutes then } \\
\text { the samples were } \\
\text { cooled and final- } \\
\text { ly squeezed and } \\
\text { dried. }\end{array}$ \\
\hline
\end{tabular}

Table 2. The experimental conditions of the coloring process

$\begin{aligned} \begin{array}{r}\text { The Quantity } \\ \text { of material: }\end{array} & 2 \text { grams } \\ & 40 \mathrm{~mL}(1: 20) \\ \text { Liquor : } & \\ \text { Temperature : } & \left.\text { Boiling Temperature (around } 98^{\circ} \mathrm{C}\right) \\ \text { Duration : } & 60 \text { minutes } \\ \text { Condition : } & \begin{array}{l}\text { After the dyeing process was concluded, the } \\ \text { samples were left to cool themselves in the } \\ \text { liquor. Then the samples were rinsed with } \\ \text { running tap water. Finally, the samples were } \\ \text { washed with the water at the boiling temper- } \\ \text { ature, rinsed with cold water and left to dry. }\end{array} \\ & \end{aligned}$

\subsection{Evaluation of the Colour Properties of the Dyed Samples}

Color measurements were performed in the color measuring device, Datacolor SF-600. All samples were measured from ten different regions of the sample and the average curves of wavelength-\%reflectance were obtained by the calculation of the arithmetic mean of the reflectance values obtained 
at the each wavelength. The calculations were performed with respect to D65 light source and 10o standard observer. For measurements, the sample which was not mordanted was accepted as standard and the samples mordanted were compared in terms of the colors. The calorimetric values were measured according to the CIELAB system. Equation 1 was used to determine total color differences [22].

$\Delta E^{-}=\sqrt{\left(\Delta L^{-}\right)^{5}+\left(\Delta a^{-}\right)^{5}+\left(\Delta b^{-}\right)^{5}}$

Where $\Delta \mathrm{E}^{*}$ refers to the total color differences. In commercial regards, if $\Delta \mathrm{E}^{*}<1$, the value of color differences could be accepted in general. The negative value of $\Delta \mathrm{L}^{*}$ demonstrate that the color of the samples compared is darker than that of the standard whereas the positive value of $\Delta \mathrm{L}^{*}$ indicates that the color of the samples compared is lighter than that of the standard. Similarly, the positive value of $\Delta \mathrm{a}^{*}$ results in surplus of the red nuance whereas the negative value of $\Delta \mathrm{a}^{*}$ results in surplus of the green nuance. The positive value of $\Delta \mathrm{b}^{*}$ points out that the yellow nuance is much whereas the negative value of $\Delta b^{*}$ indicates that the blue nuance is much.

\subsection{Evaluation of the Colour Properties of the Dyed Samples}

The light and washing fastness of the samples were tested according to ISO105-C06 [23] and ISO105-B02 [24] standards. The washing fastness of the samples was performed by using the washing fastness equipment (Gyrowash/James H.HealCo.Ltd 815/20). The light fastness of the samples was performed by using the light fastness equipment with the reference of the blue scale (Atlas Xenotest 150S).

\section{RESULTS AND DISCUSSION}

\subsection{Calculated Values of Color Differences}

The colors obtained following the coloring process of the samples mordanted with different mordants were shown in Figure 2. The differences of $\Delta \mathrm{L}^{*}, \Delta \mathrm{a}^{*}, \Delta \mathrm{b}^{*}$ and $\Delta \mathrm{C}^{*}$ are demonstrated in Figure 3.

In the spectrophotometric measurements the unmordanted samples accepted as the standard. The total color difference with respect to the ultrasonic and conventional methods $\left(\Delta \mathrm{E}^{*}\right)$ is not among the acceptable values. It is seen from the results that the ultrasonic method gave better dye uptake results than the conventional methods. And the ferrous sulphate gave better colour yield than the cupper sulphate and alum.
It is seen from the results that, the ultrasonic methods gave better dye uptake that, the ultrasonic methods gave better dye uptake results than the conventional methods. And the ferrous sulphate gave better colour yield than the copper sulphate and alum.
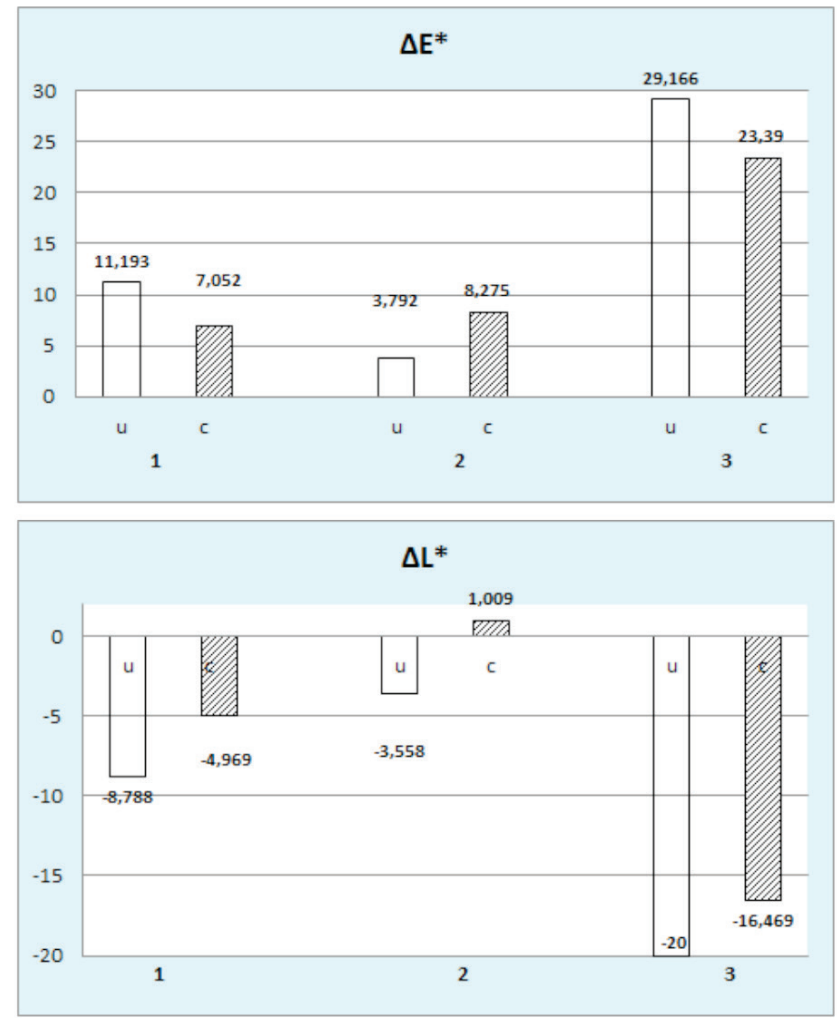

Figure 2. The colors obtained in the dyeing process. (1.Copper Sulphate (Ultrasonic Method), 2.Copper Sulphate ( Conventional Method), 3. Alum (Ultrasonic Method), 4. Alum (Conventional Method), 5. Ferrous Sulphate (Ultrasonic Method), 6 Ferrous Sulphate (Conventional Method))

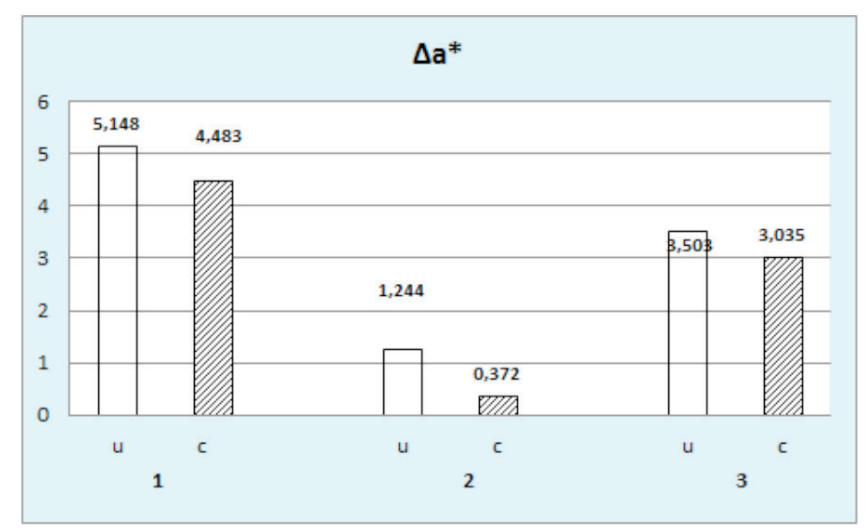



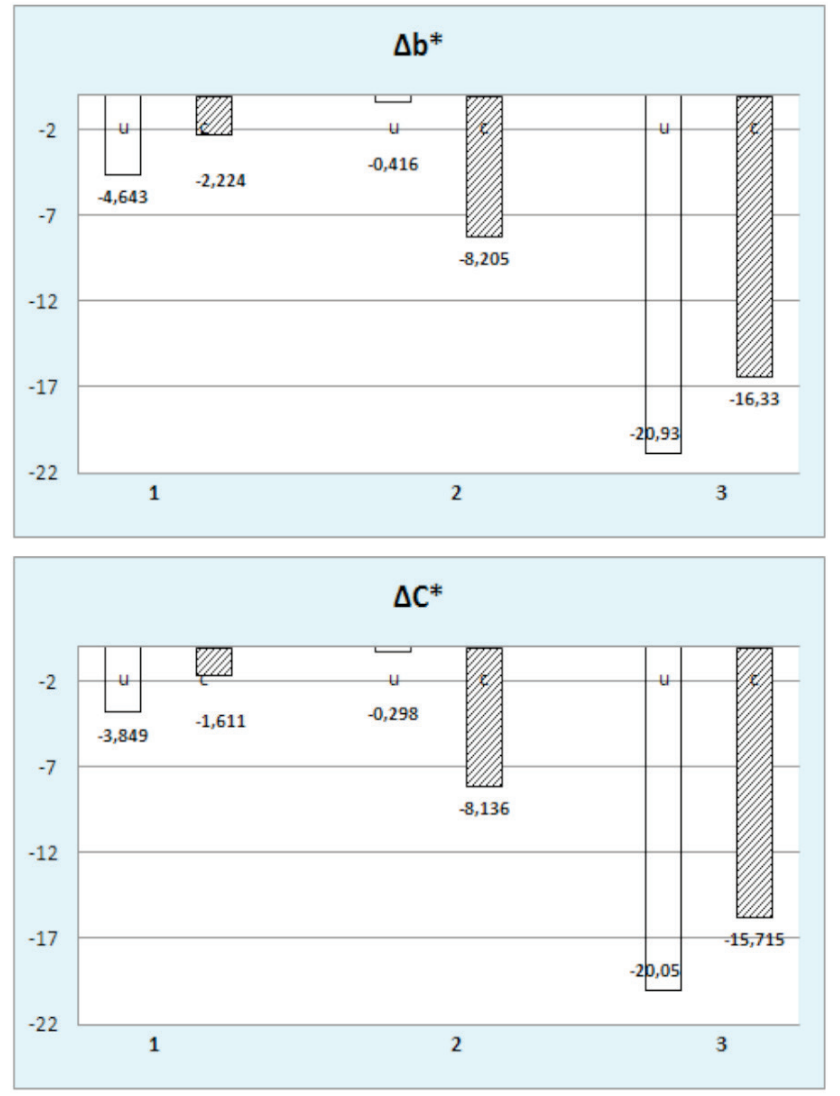

Figure 3. The color measurement values of the cotton samples. (1: Copper Sulphate, 2: Alum, 3: Ferrous Sulphate, u:ultrasonic, c:conventional)

\subsection{Results of the Color Fastness Test}

The results of the light and washing fastness tests applied to the samples are shown in Table 3.

It is seen from the colour change result that the conventional method was slightly better than the ultrasonic method for copper sulphate and alum whereas the ferrous sulphate gave better results on ultrasonic method. The staining result for all three mordants was high and almost similar colour change and light fastness at moderate level. The light fastness value was low for almost all the mordants, whereas known the light fastness of the most natural dyes is low.

\section{CONCLUSION AND ASSESSMENT}

The colours obtained by use of curcuma plants were slightly lower than the industrial requirements for the three used on this study. It is recommended to try different mordants as well as different dyeing conditions in order to improve the dyeing behavior.
Table 3. The results of washing and light fastness

\begin{tabular}{|c|c|c|c|c|c|c|c|c|}
\hline & \multicolumn{7}{|c|}{ Washing Fastness } & \multirow{2}{*}{$\begin{array}{l}\text { Light } \\
\text { Fast- }\end{array}$} \\
\hline Code & Colour & & & & & & & \\
\hline & Change & Acetate & Cotton & Polyam & lyes & Acryl & Wool & ness \\
\hline 1 & $1-2$ & 5 & $4-5$ & 4 & 5 & $4-5$ & $4-5$ & 2 \\
\hline 2 & 2 & 5 & 4 & $4-5$ & 5 & $4-5$ & $4-5$ & 2 \\
\hline 3 & $1-2$ & 5 & $4-5$ & 4 & 5 & 5 & 5 & 2 \\
\hline 4 & 2 & 5 & 4 & $4-5$ & 5 & 5 & $4-5$ & $1-2$ \\
\hline 5 & $2-3$ & 4 & $4-5$ & 4 & 5 & $4-5$ & $4-5$ & $1-2$ \\
\hline 6 & 2 & 4 & 5 & 4 & 5 & $4-5$ & $4-5$ & 2 \\
\hline
\end{tabular}

1. Copper Sulphate (Ultrasonic Method), 2.Copper Sulphate (Conventional Method ), 3. Alum (Ultrasonic Method), 4. Alum (Conventional Method), 5. Ferrous Sulphate (Ultrasonic Method), 6 Ferrous Sulphate (Conventional Method)

\section{REFERENCES}

[1] Cristea, D., Vilarem, G., Improving lightfastness of natural dyes on cotton yarn, Dyes and Pigments 70, 238-245, (2006).

[2] Deo, H.T., Desai, B.K., Dyeing of cotton and jute with tea as a natural dye, Coloration Technology, 115, 7-8, 224-227,(1999).

[3] Hunger K., "Industrial Dyes", Wiley-VCH, Weinheim, (2003).

[4] Bechtold, T., A.M., Amalid, Mussak, R, 'Natural dyes for textile dyeing: A comparison of methods to assess the quality of Canadian golden rod plant material', Dyes and Pigments, 75, 287-293, (2007).

[5] Nagia, F.A., EL-Mohamedy, R.S.R., 'Dyeing of wool with natural anthraquinone dyes from Fusarium oxysporum', Dyes and Pigments 75, 550-555, (2007).

[6] Sinha,K., Saha, P.D., Datta, S., Extraction of natural dye from petals of Flame of forest (Butea monosperma) flower: Process optimization using response surface methodology (RSM), Dyes and Pigments 94, 212-216, (2012).

[7] Slokar, Y. M. , Marechal, A.M.L., Methods of Decoloration of Textile Waste waters, Dyes and Pigments, Vol. 37, No. 4, pp. 335-356, (1998).

[8] Bhatti, I.A., Adeel, S., Jamal, M.A., Safdar, M., Abbas, M., Influence of gamma radiation on the 
colour strength and fastness properties of fabric using turmeric (Curcuma longa L.) as naturaldye, Radiation Physicsand Chemistry 79, 622-625, (2010).

[9] Bechtold, T., Turcanu, A., Ganglberger, E., Geissler, S., Natural dyes in modern textile dye houses - how to combine experiences of two centuries to meet the demands of the future, Journal of Cleaner Production 11, 499-509, (2003).

[10] Baliarsingh, S., Panda, A.K., Jena, J., Das, T., Das, N.B., Exploring sustainable technique on natural dye extraction from native plants for textile: identification of colourants, colourimetricanalysis of dyed yarns and their antimicrobial evaluation, Journal of Cleaner Production 37, 257-264, (2012).

[11] Blasco, M., García-Pérez, J.V., Bon, J., Carreres, J.E., Mulet, A., ,Effect of Blanching and Air Flow Rate on Turmeric Drying', Food Sci. Tech. Int., 12(4):315323, (2006).

[12] Araújo, C.A.C., Leon, L.L., Biological Activities of Curcuma longa L., Mem. Inst. Oswaldo Cruz, 96(5): 723-728, (2001).

[13] Sivakumar, V., Anna, J.L., Vijayeeswarri, J., Swaminathan, G., Ultrasound assisted enhancement in natural dye extraction from beetroot for industrial applications and natural dyeing of leather, Ultrasonics Sonochemistry 16, 782-789, (2009).

[14] Gogate, P.R., Cavitational reactors for process intensification of chemical processing applications: A criticalreview, Chemical Engineering and Processing: Process Intensification, 47 (4), 515-527, (2008).

[15] Akalin, M., Merdan, N., Kocak, D., Usta, I., Effects of ultrasonic energy on the wash fastness of reactive dyes, Ultrasonics,42, 1-9, (2004).

[16] Khatri, Z., Memonb, M.H., Khatri, A., Tanwari, A., Cold Pad-Batch dyeing method for cotton fabric dyeing with reactive dyes using ultrasonic energy, Ultrasonics Sonochemistry 18, 1301-1307, (2011).

[17] A. Guesmi, N. Ladhari, F. Sakli, 'Ultrasonic preparation of cationic cotton and its application in ultrasonic natural dyeing', Ultrasonics Sonochemistry 20, 571579, (2013).

[18] Kamel, M.M., Helmy, H.M., Mashaly, H.M., Kafafy, H.H., Ultrasonic assisted dyeing: Dyeing of acrylic fabrics C.I. Astrazon Basic Red 5BL 200\%, Ultrasonics Sonochemistry 17, 92-97, (2010).

[19] Kamel, M.M., El Zawahry, M.M., Ahmed, N.S.E., Abdelghaffar, F., Ultrasonic dyeing of cationized cotton fabric with natural dye Part 1: Cationization of cotton using Solfix E, Ultrasonics Sonochemistry 16, 243-249, (2009).

[20] Vankar, P.S., Shanker, R., Srivastava, J., Ultrasonic dyeing of cotton fabric with aqueous extract of Eclipta alba, Dyes and Pigments 72, 33-37, (2007).

[21]Ferrero, F., Periolatto, M., Ultrasound for low temperature dyeing of wool with acid dye, Ultrasonics Sonochemistry 19, 601-606, (2012).

[22] Fairchild, M.D., Color Appearance Models, ISBN 0-201-63464-3, AddisionWestleyLongman, Inc., (1997).

[23] ISO 105-C06 Standard

[24] TS 1008 EN ISO 105 - B02 Standard. 